\title{
The Effect of Human Resources Competencies on a Firm Performance: A Marketing Perspective (With Reference to Firms Located in UAE)
}

\author{
Ashraf Awad ${ }^{1}$ \\ ${ }^{1}$ Abu Dhabi University, Abu Dhabi, UAE \\ Correspondence: Dr. Ashraf Awad, Associated Professor, Abu Dhabi University, Abu Dhabi, UAE (Damietta \\ university- Egypt- previously).
}

Received: February 10, 2018

Accepted: March 1, $2018 \quad$ Online Published: March 22, 2018

doi:10.20849/abr.v3i1.350

URL: https://doi.org/10.20849/abr.v3i1.350

\begin{abstract}
Till date numerous theories in the field of marking has recognized both the need for improved marketing skills and the literature which provide in-depth analysis and details about such marketing skills and competencies for the help of marketing managers.

For the current work, a questionnaire was served over the managers of 162 companies, constituting 52 percent of industrial firms in Abu Dhabi. A pre-tested questionnaire having details about three prominent dimensions of leadership management, marketing and personal attributes, as measures of company performance were sent to them to analyse and to add to existing stock of knowledge on marketing skills and competency. The questionnaire turnover ratio was 77 percent, which was suitable for statistically significant analysis.

The current research has been carried out with aim to find out how much fund multi-national companies (MNCs) should allocate to Human Resource building, also to bring out competencies issues across industries, along with that to develop nexus between employee competencies and firm performance and finally to devise an appropriate mechanisms through which these relationship in companies may operate.

Findings of the current work revealed that human resource competencies on the firm performance from marketing perspectives paly its role through different channels namely organizational cultural, communication system, managing changes, knowledge sharing, employees inspiration by leaders, global completion, empowering employees, leadership competency and taking initiatives by employees.

It has been observed that performance perception, which is based on manager individual perception and a managerial style, has a negative impact on perceived benefits of creativity negligence factors. Out of nine motivating factors, only five factors were found having statistically significant impact on the competencies of firms in the selected sample of manufacturing and service industries. Analysis shows that management initiatives highlight the fact that not all of them are necessarily successful.
\end{abstract}

Keywords: HRM, competencies, performance, marketing perspective, MNCs

\section{Introduction}

Human relations among employees are an intangible element that influences employees' loyalty, productivity, retention, engagement and health (Rachid, 2010). Rephrase this whole sentence in a more technical way: previous studies suggests that sustainable success of any organization cannot be attain only through the coordination among different departments of the organization but to be successful every organisation must create an environment which allow coordination within the cooperation arrangement as well. Such contribution of cooperation for performance should be regarded as an on-going process and long term in nature. Such Also it has been observed that accomplishment of any task requiring mutual understandings and cooperation will become impossible in case of departmental contradiction, and such irregularities in coordination can be overcome through practical experience in inter-firm cooperation relationships.

Global marketing is a term used for selling goods and services via internet and also is an attempt to find new markets around the world through the channel of international distribution in this different market (Bude, and Jörg 2010). 
Multinational national companies MNCs are continuously trying to devise strategies for minimizing their cost of business, making planning process more effective and are struggling to gain competitive advantage new market. Developing local human resources then at the end in researcher opinion is not as expected as these companies have to find a balance between local customers and developing the local human resources (Khoury, et. al 2014).

In organizational learning theory, firms are supposed to have developed professional level capacity of managing complex work phenomenon, which they acquired form their continues practice and hence extrapolate them to future situations in order to achieve improvements in their behavior. Relationship between employees and employer provide opportunities for such learning (Nie, \& Lämsä, 2015). These competences grow along with the experience of its management, and the experience gained in a firm's relationship with its employees (Nie, \& Lämsä, 2015), and within such understanding both sides will decide their own communication in a credible manner. These learning experiences reinforce the initial expectations and also work as a justification for the additional acts management and employees in creating trust within the work environment. As a result, human relations relationship evolves. Therefore, both firms' experiences along with coordination and behavioural mechanism work for the successful process of building of human relations. Trust in this context is not regarded an appropriate alternative, as its institutional roots prevent are supposed to prevent any non-rational behaviours both from management and employees, and that can lead to enhance the vital role of trust in economic thinking. The firm's ability to maintain such relationships will increase their attractiveness in the market. However, unfortunately proper attention has not been given in the research to analyse the phenomenon of human relationship in economic context.

In contemporary highly competitive world, where complexities have been increasing with every day passing, the best strategy for survival is to deals innovations with the assistance of imagination and development. Firms can oversee the on-going innovation via making full utilization of organizations potential talent. Truth be told, development in administrative capacity of the firms is fuel or crude material for innovation, the main upper hand that an organization can use for maintaining in the unusual business environment. Today organization has been considering Innovation as the last approach to arrive on the plane of Success and development which must be utilized by the fullest and ideal utilization of Innovation management. To innovate effectively one must contract, work with, and bring innovation to individuals who are not all alike him, and who makes one uncomfortable in light of the fact that just those will move him for his choice. The need is to energize each kind of innovation in an organization to rouse individuals for going out on a limb and to make them realize that whatever they are doing is not optimal. Accordingly through building an inventive organization, they can guarantee their future development and achievement.

Imagination is a unique human capacity to envision things that seem impossible at present, but sometimes they may lead to innovation. On the average most of the dreams may too seems impractical but they can some time lead us towards a better life us. Another key factor that plays role is constructive curiosity and passion. Innovation is not less than an evolutionary process that never reaches a pinnacle. Legendary innovators, Darwin, Edison and Galileo possessed unbounded curiosity that led to the modern day theories and inventions. Innovation has been considered as the lifeline of contemporary better quality products, which has ultimately improved the living standards.In one way or the other these products have changed the way we ultimately live and operate. The roots of contemporary innovation can be rightly trace centuries back in the early civilizations. Since that early age innovative process has allowed the then civilization to gradually grow, and finally the society has evolved that we lives-in.

In the 21st century, nearly everyone is living on the edge of technological and exploratory innovations. Numerous innovations and revelations have been made by such a variety of extraordinary personalities whose objects were to improve our life dependably than some time recently.

Investigative and mechanical innovation is a standout amongst the most critical and broad of humankind's exertion streams all through history. Amongst many attributes, learning that how the things are done in the present day modern era is considered a positive aspect of the society. A solid and lively culture commends the soul of development and innovation.

All those individuals who are engaged in business have been constantly trying to acquire accumulate larger amount of wealth through innovation. In addition, a well-accepted reality is that organization's prosperity does not originate only from scholarly and innovative abilities. Development and data are the critical resources of a business and there is a need to figure out how to handle these benefits in new ways. Customary testing frameworks, which were intended to manage distinctive inputs and outputs are no more satisfactory to get by in the business sector. Focusing on the end goal to hold their upper hand in the current era of highly competitive 
market structures it is necessary for the organizations to sher information, data and innovation inside on one side and to adjust to external business environment promptly.

In any case, actually the benefits of innovation truly outnumber the disadvantages. Truth to be told, innovation leads to dispersion of science and philosophies, which has resulted as a development across the economies.

The current work is intended to concentrate on the effects of human resource competencies on a firm performance, from a marketing perspective in multi-national companies MNCs in the UAE.

\section{Concept of Globalization}

Globalization is an international concept. The aim of such concept is to achieve the integration or alignment of ideas, or nationwide views, products or even in societies' culture and understanding (Ritzer, 2011).

The advancement in technology and communication has made this made this integration easier. For example the internet and mobiles, may be regarded as variables generating a common understanding between peoples or new era of trading and economic activities between countries.

Irrespective of the history of globalization, when such concept was recognized, economics' relationships between nations and countries are intensified recently. More attention has been given nationwide to the volume of trade between countries, the movement of workers, foreign direct investment, and knowledge or technical know-how. Such concerns in turns are affecting globalization from socio-economic and political point of views (Murinde, Victor and Cillian Ryan, 2003).

The modern concept of globalization has its own new meanings the whole world is considered as global village. Therefore, no detriments should be established to prevent and against the variables mentioned above (i.e.... the movement of trade between countries, the movement of workers, foreign direct investment, and knowledge or (knowledge know-how).

In any situation or in any case a countries' economies or commercial transactions in its absolute meaning should not be affected is still ultimately desirable. That's Why the concerns are has been increasing every day passing many international economic activities can pose pressure on the nations' sovereignty. Examples includes but not all, multinational companies that imposes the need to implement international law which alternately can affect the internal policies for solving problems that arises between nations (Beaudet, Schafer, and Haslam, 2012). Further some other poor countries have to delegate some responsibilities or delegation authorities to the international organizations, which may affect its internal laws or norms of local communities. Also the transformation of capitals between countries may affect the internal economies of these nations. With such challenges economies in the modern world needs to devise polices in such manner that can logically protect their sovereignty and their domestic economic policies while simultaneously ensure maintaining development and prosperity. Such situations may sometimes forces nations to make choice between policies of either protecting it national values and culture norms or going ahead with globalization.

Due to many factors, it is impossible for businesses to locate their product, at every location they desire. As an example a MNCs may like to sell a specific product or service to a country in the Middle East, but it is not necessary to open a new branch in that specific country. In the researcher opinion, such activities will not affect human resource development unless MNCs format specific strategies in alliances with these nations.

Globalization is the expression mostly used and known and is discussed in different disciplines and international journals. Thus, this term is mentioned in length by different writers. Journals in politics, culture, international management, and international relationships, all have are discussed globalization from different point of views. However, and despite such widths of explanations and titles of subjects, globalization in turns for other writers means the removing of boundaries in trades and working in liberal markets (Ghosh, 2011). Above all shows that a more comprehensive meaning has been given to the term globalization.

The conclusion is that the concept of globalization implementing new ideas, and phenomenon, and due to these new understandings new markets have been establishing and economies are becoming more liberal. Thus, difficulties of shifting the goods or even capitals from one place to another should be removed and also looking for more integration in the economies. In this context the meaning and the aims of globalization has become wider (Vujakovic, 2010).

As the world has been converging to global village, the concept entitled $t$ mixing between cultures, and modern societies are formed in poor or developing countries, not only this but such understanding should become a nationwide recognized. Moreover such new understanding or expected effects of globalization should be enhanced by individuals, societies, businesses or even governments. When such expectations have positive 
effects on societies or economies, more political collaboration may contribute to new mixtures in cultures, and pave way for movement of human capital between nations (James, and Steger, 2014).

As results of above trends some scholars are postulating that new civilization has beenbuilt on mixing between cultures and a new vision by individuals was created across the borders. Such situation will enhance new objectives and visions of institutions or even new commitment with poor's.

The above discussion may lead to the exploration of a new dimension of globalization which is important to be given proper consideration by nations or new visions and objectives of businesses. Truth to be told we have to realize that the other side of the coins has a negative aspect concerning globalization in terms the meaning and the cause why we accept this concept (Wolf, 2014).in nutshell globalization is such a controversial topic that it has got no single definition which globally accepted .

\subsection{Nexus Between Human Resource and Globalization}

The researcher advocate that for the MNCs should work towards the development of local human resources and in this regard ethical issue must to be kept on the top of priority list. The success of multination marketing strategies depends upon local industries of the host country which can work as a barrier in the way of smooth transition towards the development of local human resources (Berch, 2010). Also the local logistics, available local data and trends may not have the potential to accept such development of MNCs when entering international markets. Such situations need insight of the local human resources and incorporating culture in their marketing strategies to drive the best strategies by these companies and will help these companies to choose the proper market position, even how to help in developing the local human resources within their global marketing strategies. The knowledge of local individuals and experts should be considered by these companies at the time of devising their policies. Each country has its quirks and this is a customized message (Berg and Ostry2011).

Efficient human resources are supposed to accept such development in the and concepts of globalization. Involving human resources with globalization meanings or effects is accepted by the majority of writers or article concerning globalization. More than that, any discussions will be fair and accepted nationwide. On the other hand for human resources has different meaning or situation which needs differentiation, such as superiority of the State (the host country) or of a specific nation, interference and type of government of the State, or imposing power on the local industries (George and Zeynep, 2010), which in turn affect local human resources.

In general there are two different understanding of interpreting the relationship between the human resources and the concept of globalization on competency. On one hand it is widely accepted that there is no effect of globalization on the conduct of local businesses. Such advocacy postulate the two concepts as mutually exclusive in terms of cause and effect and assume that changes in the business environment will not change the human resources contribution towards competency concept positively (Fuller and Geide-Stevenson, 2003). The rival school of thought on the nexus between globalization and local human resource development hold the opinion that globalization will always negatively affect the local market hence there is no need of globalization.

The above discussion revealed that due to controversies in the meaning and concept of globalization among politicians and economist, it is still merely concept and not a system either economically or culturally accepted.. Therefore it is not a liberal exchange of labor from one place to another, shifting technologies or working in a free market concerning products or capitals for improving competencies. It becomes an aspiration of shifting foreign direct investments between countries to establish an economic international system accepted nationwide or positively aspects related to performance or competencies (Seguino, and Grown, 2006).

Talking about competencies, means we are refereeing to an organization success in the working environment. In this context employees should believe in their leadership capacities for achieving their organizational objectives, also trusting each other. In such relationship between management and its employees on one side and between employees themselves on the other side, teamwork building, communication and performance inevitably enhanced in the workplace (Xu, Joyce, Aili, \&Yaping, 2010).

In business environment forming a conscious teamwork with a well-defined plan is the most essential variable for achieving organization success, as employees will react promptly, will be able to overcome obstacles, will enhance their competencies and finally will result in better performance (Liping, Onne, \& Kan, 2010). Alternatively building competencies means establishing a high performing team within the organization based on shared values creation, and leadership/management openness with employees. Such understanding of building relationship will enhance a two-way interaction and improving organizational performance. 


\subsection{The Impact of Competencies on Organizational Performance}

Early marketing is a term, used to refer the organization ability to forecast the success or the failure of the MNCs of their marketing strategies. Business enterprises study various aspects of markets before entering them in order to ensure their survival, and to examine every potential opportunity of success. Altering the products and the services or abandoning altogether may affect MNCs in setting their strategies.

Any organization, which has been trying to ensure that its employees make good decisions, managers have often started with building competencies. Management will soon realize that competencies and telling their employees what to do without sensitivity imply that such management has faith in their decision-making abilities. This can result in becoming proactive rather than defensive. In addition, the employees can enhance their faith in their own confidence to make decisions. When the employees do not have faith in them, then the manager's faith in them gradually decreases even more and building trust begins again ( $\mathrm{Lu}, 2014)$. Thus the negative message is that what the employee has done is wrong or not good enough.

Managers have to evaluate their employees from their own point of view and then giving them the required assignments, and the strategy is to cultivate the habit of listening to them. The feeling is a positive one towards the employees. Also, managers should not interrupt their employees who are attempting to communicate, acknowledgment by their managers, and also keep positive and cooperative behaviour towards them. In such environment mangers well acknowledged their employees' feelings and opinions. In fact it is the only way to that can ensure improvement in communication and building competencies (Andersen, 2016).

For managers it is very crucial to let their employees know what they are willing to listen, even though it may not results in agreement of both sides (Jacqueline, 2012). Such working relationship environment is purely based on confidence, as both sides feel safe and the implicit message is each other's best interests in mind. Employees can accept their managers' criticism, at the same time having their confidence. Thus, to have the optimum working relationships managers/employees should feel a sense of trust. In this context managers know that delegation of tasks is essential for building competencies within the workplace environment, and do not deprive their employees of any opportunity to advance their skills, knowledge, experience and to improve performance. Within such environment, Among employees' a feelings of trust is developed and they start realising that their management have been treating them as an asset for organization and as a resourceful individual, and empowering them to improve their performances. The next step is to focus on the progress made by the employees, something positive achieved and still more expectation to maintain (Bano, 2013). This is regarded as a positive step for employees' incentives for doing their tasks, thoughts and communications.

The absence of trust between leadership and employees in any organization will erode the process of communication, teambuilding, and competency (Abraham, Asher, \& Amy, 2012). Thus these three may be considered as crucial elements of the strategies used by this management to improve its employees' performances. Without that, employees' turnover will be high and also their moral level at the workplace is in the low ebb. Such elements are regarded as catalyst for making an innovative, profitable and creative environment and organizations to work.

New knowledge and collaboration schemes has been developed and led by globalization. Virtual teams were assumed to play role in managing and understanding the new knowledge to foster effectiveness of using the available resources which is becoming a critical interest and more relevant for the multinational companies. Such new knowledge may sometime become a challenge in many aspects of doing businesses in these innovative companies, as it may requires evaluation of the organization intangible assets which are important for employees' initiatives.

Knowledge sharing within the organization is necessary on the grounds that it helps to eliminate the stale information phenomenon, exploiting time positively for entering the market, optimizing the flow of information to the employees, improving the quality of assignments or tasks and in articulating the work process to the employees (Kim, and Yoon, 2015).

In general sharing information and knowledge within the organization will help in using the available resources effectively and efficiently, and using the available information in product's creation processes.

Sharing knowledge effectively will help organizations in monitoring the flow of such valuable enablers to improve the employees' experiences and personal experience simultaneously. Working on this path has its implication on managers and the human resources of the organization and trace the relevant information in virtual teams. 


\section{Methodology and Analysis}

The present study has employed survey method for collecting data from the leadership/management of companies includes in the study sample. Stratified sampling procedure has been utilized to select appropriate sample from the population. Questionnaires were sent to the managers of 162 companies (representing more than $52 \%$ of the industrial firms in Abu Dhabi) with significant responsibility for leadership/management as human resources competencies contribution to motivating performance. With turnover ratio of $77 \%, 125$ managers completed and send back questionnaires.. Measures were adopted and used to weigh each of the (9) variables of motivating human resources and improving their competencies, namely: The organizational culture, The communication system, Managing changes, Knowledge sharing, Employees' inspiration by leaders, Global competition, Empowering employees, Leadership competency and Taking initiatives by employees.

Only five motivators were found to have significant impact on motivating human resource competencies and improving firms' performance for the organizations selected in the sample. One-way ANOVA analysis is used to assess the similarities in the clusters. A five-point likert scale, where responses were ranked from 1 (strongly disagree) to 5 (strongly agree) has been utilized. The research is intended to investigate the status of these constructed variables as enablers for motivating trust in industrial sector (Table1).

From Table 1, the F-statistic value, among factors motivating, trust factors within the companies surveyed in the sample was high and significant with probability value of 0.01 . On the basis of F-statistic value indicators are ranked as organizational culture, knowledge sharing, and employees' inspiration by leaders, global competition and empowering employees with F-statistic: 5.55, 6.11, 5.15, 11.17, and 8.70 respectively. Global competition has got first rank, empowering employees the second, knowledge sharing is on the third rank, the organizational culture is on the fourth rank and employees' inspiration by leaders is the last rank. Using $P$-value method, leadership competency was found 0.78 , and the organizational culture is the least 0.12 . However such $P$-value has a rather high value. The alpha value of 0.91 indicates that the research instrument enjoys a rather high validity.

Table 1. Factors motivating competencies: performance

\begin{tabular}{|c|c|c|c|c|c|c|c|}
\hline \multirow[t]{2}{*}{$\begin{array}{l}\text { Factors Encouraging } \\
\text { Performance }\end{array}$} & \multicolumn{2}{|c|}{ Service Firms } & \multicolumn{2}{|c|}{$\begin{array}{l}\text { Manufacturing- } \\
\text { Industrial Firms }\end{array}$} & \multicolumn{3}{|c|}{$\begin{array}{l}\text { One-way ANOVA \& } \\
\text { Scheffe's test }\end{array}$} \\
\hline & Mean & SD & Mean & SD & F-stat & P-value & ST \\
\hline The organizational culture & 4.11 & 0.84 & 4.69 & 0.52 & 5.55 & 0.12 & \multirow{9}{*}{$\begin{array}{l}\text { III }>\text { II, } \\
\text { III }>\text { I, } \\
\text { III }>\text { I }\end{array}$} \\
\hline $\begin{array}{l}\text { The communication } \\
\text { system }\end{array}$ & 4.51 & 0.64 & 4.45 & 0.64 & & 0.38 & \\
\hline Managing changes & 3.21 & 0.85 & 3.16 & 0.53 & & 0.30 & \\
\hline Knowledge sharing & 4.47 & 0.53 & 4.75 & 0.58 & & 0.05 & \\
\hline $\begin{array}{l}\text { Employees' inspiration } \\
\text { by leaders }\end{array}$ & 4.21 & 0.82 & 3.95 & 0.99 & & 0.17 & \\
\hline Global Competition & 3.90 & 0.74 & 3.95 & 1.00 & & $0.00 *$ & \\
\hline Empowering employees & 2.90 & 0.61 & 3.41 & 0.78 & & $0.00 *$ & \\
\hline Leadership competency & 3.80 & 0.64 & 3.62 & 0.94 & & 0.78 & \\
\hline $\begin{array}{l}\text { Taking initiatives by } \\
\text { employees }\end{array}$ & 4.04 & 0.70 & 4.54 & 0.61 & & 0.18 & \\
\hline
\end{tabular}

ST: Scheffe's test

The mean values on five-point likert scale $(1=$ strongly disagree; $5=$ strongly agree) of the five indicators concerning motivating trust were: $20.46,21.39,15.11,39.68$ and 22.67 for the organizational culture, knowledge sharing, employees' inspiration by leaders, global competition, empowering employees respectively. The mean value of global competition is 39.68 which is highest in ranking, indicating that management in the firms surveyed are encouraging diversity at work and are welcoming the open door system, high participation for employees in the decision making process, and are aware of the fact that motivating trust plays a significant role in the success of the organization. The P-value of 22.67 for empowering employees indicates that solving organization problems 
through teamwork was high and the management empowering their employees with the responsibility. This indicator is compatible with the third ranking elements; the knowledge sharing has the P-value of 21.39. In fact, the respondents believe that management and employees in the selected firms have been judged properly, by what they do and the knowledge of departing employees is not passed pervasive on to successors. In fact, such issues reflect that these companies have a suitable network of knowledge sharing workers, further they believes that there is an active program for developing ideas. The organizational cultural element is on the fourth rank with P-value of 20.46. From the score the clear interpretation for such situation is that the employees and their companies have been acting rather effectively in case of regular and wide exchange of knowledge, and using of information system and communication have been higher than average. Employees' inspiration by leaders has got the least rank with a mean value of 15.11. The lowest value indicates that employees have had simple knowledge about the trust concept. The mean value of performance motivation factors was 121.731 , which indicates that respondents in the selected sample believed that management efforts for performance concept between employees with respect to the present criteria along with the companies' internal environment were less than the average (Table 2).

Table 2. Statistics analysis

\begin{tabular}{lllll}
\hline The Enablers & Mean & SD & Kurtosis & Skewness \\
The organizational Culture & 20.46 & 9.9 & -0.086 & -0.635 \\
Knowledge sharing & 21.39 & 10.9 & -0.224 & -0.753 \\
Employees' inspiration by leader & 15.11 & 9.3 & -0.293 & -0583 \\
Global competition & 39.68 & 12.3 & -0.334 & -0.535 \\
Empowering employees & 22.67 & 11.3 & -0.100 & -0.119 \\
Total Factors Motivating Performance & 121.731 & & & \\
\hline
\end{tabular}

While discussing Questionnaire with managers in the companies surveyed, the researchers have asked respondents to elaborate on their answers. Respondents mentioned numerous other motivational factors which they have worked on for improving performances of their respective firms. The researchers believe that leadership/managers' education was probably behind such improved revelations. Motivational factors mentioned by those managers can technically be categorized as: internal or external competition, organizational culture, no fear of criticism by the management, availability of financial and economic resources, and management risk tolerance. To assess if the education element is behind such problems' expectations, we used the Kruscal-Wallis techniques. Results are presented in (Table 3).

The results in Table 3 revealed that there is a relationship among factors ;global competition, empowering employees, knowledge sharing, total performance motivational factors with employees' and the managers' education level. With $(\mathrm{K} \partial f=2.000, \mathrm{P}<.01)$, the value of the construct variables are: $(\mathrm{K} \partial f=38.380)$, $(\mathrm{K} \partial f=22.287)$, $(\mathrm{K} \partial f=18.954)$ and $(\mathrm{K} \partial f=21.932)$. There was no significant difference between education and the other two motivational variables (i.e., employees' inspiration by leaders and the organizational culture).

Table 3: Kruscal-Wallis Test

\begin{tabular}{lllllll}
\hline & $\begin{array}{l}\text { Global } \\
\text { competition }\end{array}$ & $\begin{array}{l}\text { Empowering } \\
\text { employees }\end{array}$ & $\begin{array}{l}\text { Knowledge } \\
\text { sharing }\end{array}$ & $\begin{array}{l}\text { The } \\
\text { organizational } \\
\text { Culture }\end{array}$ & $\begin{array}{l}\text { Employees' } \\
\text { inspiration } \\
\text { by leaders }\end{array}$ & $\begin{array}{l}\text { Total Factors } \\
\text { Motivating } \\
\text { performance }\end{array}$ \\
$\begin{array}{l}\text { Chi-Squ } \\
\text { are }\end{array}$ & 38.380 & 22.287 & 18.954 & 10.994 & 9.226 & 21.932 \\
$\begin{array}{l}\text { Asymp. } \\
\text { Sig. }\end{array}$ & 0.000 & 0.000 & 0.000 & 0.722 & 0.246 & 0.032 \\
$\boldsymbol{\partial f}$ & 2.000 & 2.000 & 2.000 & 2.000 & 2.000 & 2.000 \\
\hline
\end{tabular}




\section{Conclusions}

The international monetary fund is concentrating on MNCs through the globalization concept as a means for nations or country independence and development. Such interpretation may be achieved through movement of capital, labors, technology, knowledge and goods and services between nations' economies and regions.

The findings of the current work revealed that the leadership/management in the MNCs is aware of the fact that competencies works as an enablers of positive contribution towards high performance. Thus building working environment in an organization depends on its experience, and enhancing the coordinative power within its managements' efforts.

In the current research the relationship between building employees' competencies and organizational performance was explored, and have also indicated the mechanisms through which such relationships may operate in the workplace. Employees' competencies by their managers in the workplace environment has explicitly influenced those employees to accept the changes that organization intent to consider. So it can be concluded That e that there are importance between employees' confidence for workplace performance and the level of such relationship influenced by job and work related characteristics. Alternatively it can be said that , competencies are the key builder for considering positive changes, it may also have the negative impact due to the lack of confidence. Hence low level of confidence may undermine management's efforts for changes, and leadership/management has to understand and to be aware of the performances of their organization employees.

Managers may be demonstrating competencies through an environment characterized by transparency, involving employees in the decision making process, problem solving and openness with the employees in the workplace. In other words the organizational structure is signaling relationship between them. Using active rather than passive methods of communication by the managers with employees is helping in maintaining and enhancing competencies in the workplace environment. Also transparencies in communication from the both sides are helping in removing the ambiguity of changes and the employees' resistance for such changes. This will help the management to achieve the required outcome.

\section{Limitation of the Study}

In light of our empirical results, further research in this field is certainly worthwhile, both from a scientific as well as a practical point of view. More research about competencies in terms of a major challenge with regard to the autonomy of the respondents to assess if the findings are regarded as a cultural context in other industries.

\section{References}

Andersen, A. (2016). Anoldmanandthe, sea of leadership. Journal of Leadership Studies, 9(4), 70-81. https://doi.org/10.1002/j1s.21422

Abraham, C., Asher, T., \& Amy, E. (2012). CEO relational leadership and strategic decision quality in top management teams: The role of team trust and learning from failure. Strategic Organization, 10(1), 31-54. https://doi.org/10.1177/1476127011434797

Bano, B. (2013). An empirical study on effect to transformational leadership on organizational commitment in the banking sector of Pakistan. IOSR Journal of Business and Management, 8(2), 38-44. https://doi.org/10.9790/487X-0823844

Beaudet, P., Schafer, J., \& Haslam, A. (2012). Introduction to International Development: Approaches, Actors, and Issues. Oxford University Press, 112.

Berg, G., \& Ostry, D. (2011). Equality and Efficiency, Finance and Development. International Monetary Fund. $48(3)$.

Bude, H., \& Jörg, D. (2010). What is Wrong with Globalization? Contra "flow speak" - Towards and Existential Turn in the Theory of Globalization. European Journal of Social Theory, 13(4), 481-500. https://doi.org/10.1177/1368431010382761

Clayton, T. (2004). Competing conceptions of globalization" revisited: Relocating the tension between world-systems analysis and globalization analysis. Comparative Education Review, 48(3), 274-294.

Fuller, D., Geide-Stevenson, D. (2003). Consensus Among Economists: Revisited, (PDF). Journal of Economic Review, 34(4), 369-87. https://doi.org/10.1080/00220480309595230

Ghosh, B. (2011). Cultural Changes and Challenges in the Era of Globalization. Journal of Developing Societies, SAGE Publications, 27(2), 153-75. https://doi.org/10.1177/0169796X1102700203 
Berch, B. (2010). Globalization in the $21^{\text {st }}$ century: labor, capital, and the state on a world scale. New York: Palgrave Macmillan.

James, P., \& Steger, B. (2014), A Genealogy of globalization: The career of a concept. Globalizations, 11(4), 417-34. https://doi.org/10.1080/14747731.2014.951186

Jacqueline, B. (2012). The Shared Leadership Process in Decision-Making Teams. The Journal of Social Psychology, 152(1), 17-42. https://doi.org/10.1080/00224545.2010.538763

Kim, S., \& Yoon, G. (2015). Aninnovation-driven culture in local government: Do senior manager's transformational leadership and the climate for creativity matter?. Public Personnel Management, 44(2), 147-168. https://doi.org/10.1177/0091026014568896

Khoury, K., Bjorkman, D., Dempewolf, H., Ramirez-Villegas, J., Guarino, L., Jarvis, A., Rieseberg, H., \& Struik, C. (2014). Increasing homogeneity in global food supplies and the implications for food security. PNAS., 111(11), 4001-06. https://doi.org/10.1073/pnas.1313490111

Lu, Xiaojun. (2014). Ethical Leadership and Organizational Citizenship Behavior: The Mediating Roles of Cognitive and Affective Trust. Social Behavior and Personality: An International Journal, 42(3), 379-389. https://doi.org/10.2224/sbp.2014.42.3.379

Liping, G., Onne, J., \& Kan, S. (2010). Leader trust and employee voice: The moderating role of empowering leader behaviors. The Leadership Quarterly, 22(4), 787-798.

Murinde, Victor, \& Cillian, Ryan. (2003). Gulf Banking and the WTO's General Agreement on Trade in Services. The Emirates Occasional Papers, Abu Dhabi the Emirates Center for Strategic Studies \& Research.

Nie, D., \& Lämsä, M. (2015). The Leader-Member Exchange Theory in the Chinese Context and the Ethical Challenge of Guanxi. Journal of Business Ethics, 128(4), 851-861. https://doi.org/10.1007/s10551-013-1983-9

Ritzer, G. (2011). Globalization: the essentials. UK: Chichester, Madlen. MA: Wiley-Blackwell.

Rachid, Z. (2010). Towards a two - factor theory of interpersonal trust: a focus on trust in leadership. International Journal of Commerce and Management, 20(3), 246-257. https://doi.org/10.1108/10569211011076938

George, R., \& Zeynep, A. (2010). Readings in globalization: key concepts and major debates. UK: Chichester, Madlen. MA: Wiley-Blackwell.

Vujakovic, P. (2010). How to Measure Globalization? A New Globalization Index (NGI). Atlantic Economic Journal, 38(2), 237. https://doi.org/10.1007/s11293-010-9217-3

Wolf, M. (2014). Shaping Globalization (PDF). Finance \& Development, 51(3), 22-25.

Xu, H., Joyce, I., Aili, L., \& Yaping, G. (2010). Does participative leadership enhance work performance by inducing empowerment or trust? The differential effects on managerial and non-managerial subordinates. Journal of Organizational Behavior, 31(1), 122-143.

\section{Copyrights}

Copyright for this article is retained by the author(s), with first publication rights granted to the journal.

This is an open-access article distributed under the terms and conditions of the Creative Commons Attribution license (http://creativecommons.org/licenses/by/4.0/). 